\title{
Curriculum Implementation: A Mammoth Task for Instructional Leadership
}

\author{
Mutendwahothe Walter Lumadi \\ Department of Curriculum and Instruction, College of Education, \\ University of South Africa, South Africa \\ Lumadmw@unisa.ac.za
}

Doi:10.5901/mjss.2014.v5n6p203

\begin{abstract}
South African secondary education is marred by crises of varying dimensions and magnitude, which combined; suggest that the system is at a crossroads. Poor examination results are always related to failure and they tarnish the image of the school. However, satisfactory results are related to success, and they reward the instructional leader and his or her team by giving them a good reputation. Although the overall Grade 12 results in South Africa reflect an improvement in performance, the Eastern Cape (EC) and Limpopo (Limp), as usual, are at the bottom of the provincial list. Learners fail dismally in Mathematics and Physical Science and this has a profound effect on the training of the country's future professionals such as medical doctors and engineers. It is against this backdrop that the study explored the factors that contribute to the low pass rate of Grade 12 learners, in the two above-mentioned provinces, from 2010 to 2013. A qualitative approach was adopted in the study and interviews were conducted to collect data. The findings that emerged from the study were the unsafe environment and lack of job security. On the basis of the findings, recommendations were formulated to equip instructional leaders with strategies for the effective implementation of the curriculum.
\end{abstract}

Keywords: Curriculum implementation, instructional leadership, Eastern Cape, Limpopo and Vhembe district

\section{Introduction}

The concept of "instructional leadership" was first brought to the attention of school principals at the beginning of the effective schools movement during the 1980s in the United States of America (USA) (Leithwood \& Jantzi, 2000; Glickman, Gordon, \& Ross-Gordon, 2001). The movement continues to promote ideas on how principals should meet the educational challenges of the new century (Duignan, 2006; Murphy, 1990). The term is also used as a synonym for "curriculum or educational leadership", denoting a focus on the primary purpose of schools. Most instructional leaders complain about the taxing demands on their time by others, inter alia, parents, staff, learners, members of school governing bodies and community organisations. One needs to take cognisance of the fact that these individuals and groups compete with one another, not only because they vie for the principals' time and attention, but because they have different perspectives and motives. Consequently, principals experience the challenge of reconciling conflicting sets of goals in order to satisfy a range of stakeholders.

\section{Literature Review}

Competent instructional leaders believe that the problems of the school are their problems, and they never stop trying to solve them. If a student encounters challenges when learning, a successful principal knows it is his or her responsibility to determine whether the learner has a learning disability, has to cope with poverty or background-related problems, experiences problems attending school or is involved in gangs. Effective instructional leaders are also creative in their problem solving and approach challenges with an entrepreneurial attitude. They find ways to implement good ideas, instead of simply accepting the status quo (Posner, 1995). Instructional leaders should ensure that the classroom situation (involving the three major components - the teacher, the learner and the learning content) is conducive to learning (see figure 1, which illustrates the three major components of curriculum implementation). 


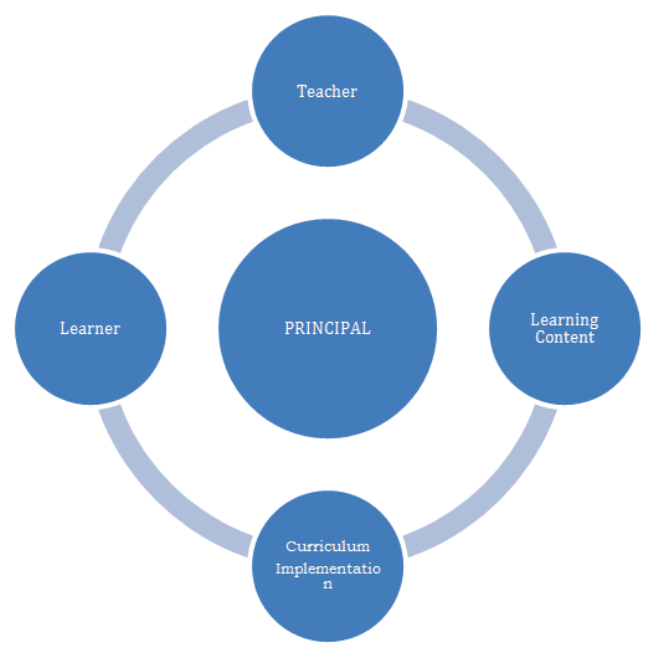

Figure 1: Curriculum implementation

Instructional leaders can have a positive influence on tense situations, thereby helping to resolve problems with teachers and learners. A collegial model which focuses on equal participation in a school is required in each situation. A challenge for educational leaders is to build cultures of capability where all teachers feel that they are valued and that they can contribute to the leadership of the organisation. Capable leaders need to have adequate knowledge, understanding and skills to manage their responsibilities and resolve complex problems. The ultimate challenge for instructional leaders is to develop their own and others' capabilities so that their schools can flourish in complex, uncertain, unpredictable and rapidly changing environments (Duignan, 2006). Although the classroom teacher is the most visible person in a learner's life at school, the principal is responsible for providing a high-quality education for all the learners in the school. Principals have difference strategies, temperaments and leadership styles, but efficient and effective principals need to be able to do the following:

* assume responsibility for the school's success

* lead teaching and learning

* hire, develop and retain excellent teachers

* build a strong school community

Leithwood Jantzi, and Steinbech, (1999) identify the following dimensions of instructional leadership: formulating the school's vision and goals; providing intellectual stimulation; rendering individualised support; symbolising professional practices and values; demonstrating high performance expectations; and developing structures to foster participation in school decisions.

\subsection{Context of the study}

Of the nine provinces in South Africa, the Western Cape, was the best with a pass rate of 82.9\%, while the Eastern Cape (EC) and Limpopo (Limp), with a pass rate of 58.1\% and $57.9 \%$ respectively, fared worse than they had in 2010 (see table 1 for Grade 12 results in 2010 to 2013 in ascending order).

Table 1: Grade 12 results in 2010-2013 in South African provinces

\begin{tabular}{|l|c|c|l|}
\hline \multicolumn{1}{|c|}{ Province } & 2013 & 2012 & \multicolumn{1}{c|}{ Difference } \\
\hline Eastern Cape (EC) & $58.1 \%$ & $58.3 \%$ & A decline of 0.2\% \\
\hline Limpopo (Limp) & $63.9 \%$ & $57.9 \%$ & A 6\% improvement \\
\hline Mpumalanga & $64.8 \%$ & $56.8 \%$ & An 8\% improvement \\
\hline KwaZulu-Natal & $68.1 \%$ & $70.7 \%$ & A decline of $2.6 \%$ \\
\hline Northern Cape & $68.8 \%$ & $72.3 \%$ & A decline of 3.5\% \\
\hline Free State & $75.7 \%$ & $70.7 \%$ & A 5\% improvement \\
\hline
\end{tabular}




\begin{tabular}{|l|l|l|l|}
\hline North West & $77.8 \%$ & $75,7 \%$ & A 2.1\% improvement \\
\hline Gauteng & $81.3 \%$ & $78.6 \%$ & A 2.5\% improvement \\
\hline Western Cape & $82.9 \%$ & $76.8 \%$ & A 6.1\% improvement \\
\hline
\end{tabular}

The five poorest performing districts were Butterworth, Fort Beaufort, Libode, Mt Frere and Sterkspruit (all in the Eastern Cape). Of the other ten poorly performing districts, six were in the Eastern Cape (Dutywa, King Williams Town, Lusikisiki, Mbizana, Queenstown and Qumbu), one in Obonjeni in KwaZulu-Natal, two in Limpopo (Waterberg and Vhembe), one, Bohlabela, in Mpumalanga, and one, John Taolo Gaetsewe, in the Northern Cape. The Eastern Cape was formed in 1994 from the independent Xhosa homelands of Transkei and Ciskei, together with the eastern portion of the old Cape Province. The capital of the Eastern Cape is Bhisho, but its two largest cities are Port Elizabeth and East London. The schools in Limpopo included in the sample were from the Vhembe district where the education department is located in Thohoyandou, 180 kilometres from Polokwane. The schools in the Vhembe district were from the following four circuits: Sibasa, Dzindi, Vhuronga 1 and Sagole, as indicated in table 2. The schools in the Eastern Cape were from the following four districts; Lusikisiki, Qumbu (70 km from Mthatha), Queenstown (72 km from Port Edward in KwaZulu-Natal) and King Williams Town, which is closer to Bhisho (see table 3).

\section{Method}

A qualitative method was adopted in this study with interviews used as the research tool for data collection. The study used purposive sampling with 16 secondary schools selected as sites for the study, two from each of the four districts in the Eastern Cape, and eight from the Vhembe district in Limpopo. With the assistance of the Eastern Cape and Limpopo Departments of Education, the schools selected from these districts were chosen on the basis of their poor 2010 to 2013 Grade 12 results. The participants were categorised as follows:

$>$ Sixteen secondary school principals ( 2 from each of the 4 circuits in the Vhembe district in Limpopo and 2 from each of the 4 districts in the Eastern Cape) were included in the purposive sample from a population of 86.

$>$ Principals with seven years or more years of experience were included.

> Sixteen (16) Grade 12 Mathematics and Physical Science teachers, eight from each province were included. Each circuit and district was represented by four teachers, two for each subject, and included in the purposive sample from a population of 156 .

> Teachers with five or more years of experience were included (see table 3 for details of participants).

$>$ The above teachers were all members of the school management team.

Table 2: Circuits included in the sample from the Vhembe District in Limpopo

\begin{tabular}{|cl|c|c|}
\hline \multicolumn{1}{|c|}{ Circuit } & Subject and number of teachers & \\
\hline & Mathematics & Physical Science \\
\hline o & Sibasa & 02 & 02 \\
\hline o & Dzindi & 02 & 02 \\
\hline o & Vhuronga 1 & 02 & 02 \\
\hline o & Sagole & 02 & 02 \\
\hline Total & 08 & 08 \\
\hline
\end{tabular}

The above table shows the number of circuits included in the purposive sample from the Vhembe district in Limpopo, while table 3 provides details of the participants from both provinces in South Africa.

Table 3: Details of participants in the Eastern Cape and Limpopo

\begin{tabular}{|c|c|c|c|c|c|c|c|}
\hline \multirow{2}{*}{\multicolumn{2}{|c|}{\begin{tabular}{|l} 
Districts \\
Participants
\end{tabular}}} & \multirow[t]{2}{*}{ Lusikisiki } & \multirow[t]{2}{*}{ Qumbu } & \multirow[t]{2}{*}{ Queenstown } & \multirow[t]{2}{*}{ King Williams Town } & \multirow[t]{2}{*}{ Vhembe } & \multirow[t]{2}{*}{ TOTAL } \\
\hline & & & & & & & \\
\hline$\checkmark$ & Principals & 02 & 02 & 02 & 02 & 08 & 16 \\
\hline$\sqrt{ }$ & Teachers & 04 & 04 & 04 & 04 & 16 & 32 \\
\hline Total & & 06 & 06 & 06 & 06 & 24 & 48 \\
\hline
\end{tabular}




\section{Findings and Discussion}

The sixteen principals gave their perspective on the factors that contribute to the high failure rate of Grade 12 students in Mathematics and Physical Science in the two provinces. Analysis of the data involved transforming and modelling the data in order to highlight useful information, suggest results and support decision making. The following themes emerged from the interviews with the various participants:

\subsection{Theme 1: unsafe environment}

School safety is essential for providing a safe environment in which all teachers, regardless of their positions, can work with minimal risk to their health. On-the-job accidents may cause injuries and death to staff members or learners. Preventing such accidents is the task of the school principal. All schools should provide safety training and follow safety protocols to prevent injuries or harm to teaching staff (Maehr, 1991). The poor results at some of schools in the Eastern Cape and Limpopo were caused by the poor safety and security measures on school premises. In schools where safety is poor, teachers' efforts to produce good results tend to be futile. Participant $Y$ from the Qumbu district mentioned the following about his school:

"It was at this school where a pregnant teacher was shot whilst writing on the chalkboard. It was all over the media, in newspapers, radios and televisions. She was hospitalised for a month. It was unfortunate that she had a miscarriage. The husband sued the Department of Education and the teacher was forced to resign in view of this unenviable situation. The Grade 12 students stayed without a Science teacher for a month."

Principals reported the following two incidents in other Eastern Cape districts:

* "The argument ensued between a Learner Representative Council student and a popular Mathematics teacher. The teacher was later hacked by an axe in the presence of all students. This teacher was redeployed to another district within the same Province. Apart from holding an Honours degree from Rhodes University he was popular for producing good Grade 12 results."

* "In 2011, two male students were summoned to the principal's office for bullying females. When the principal was about to issue written warnings, he was stabbed in his office. These students were under the influence of liquor and drugs. A deputy principal, who came to the principal's rescue, was held hostage for several hours. You can guess about the Grade 12 results in a dysfunctional school."

The rate of school violence in the Eastern Cape and Limpopo is increasing and has endangered the lives of many teachers in numerous ways. Owing to the above issues, teachers are always uncertain about security because of the fluidity of the situation in certain schools. Principals and teachers should heed any subtle warnings of potential confrontation. Potential school violence is often related to gang confrontations, problematic drug deals or personal animosity. In most instances, the learners hear about potential violence before it occurs.

To ensure a safe classroom environment, teachers have to encourage an open but authoritative relationship with the learners. This encourages learners to feel comfortable about discussing potential safety problems with their teachers. Furthermore, an open and friendly classroom environment helps all learners feel comfortable and involved in both classroom and social activities. This reduces the risk of learners engaging in dangerous behaviour because many acts of school violence are fundamentally acts of social rebellion. A friendly and calm learning environment promotes successful learning, and in such conditions, good results can be achieved in any classroom. A principal from school $Y$ in the Vhuronga circuit in the Vhembe district commented as follows on the issue of transport:

"The walking distance to this school is a force to be reckoned with. Some students walk for $35 \mathrm{~km}$ single trip in the morning. In the afternoon they have to foot home another $35 \mathrm{~km}$. The only snag is that they have to cross a river by means of swimming and in the process books get wet or lost. Last month, a corpse for our Grade 12 student was discovered after being washed away by a river. It was heartbreaking in a funeral to see a weeping single mother who was left devastated. Most Grade 12 students are always absent when the river is full because there is no scholar transport from their homes to schools. These students are exempted from attending the morning and afternoon studies. When Grade 12 students were busy with examinations, a student was raped in the bush coming to school. The matter was reported to the police station. The same student who was raped failed in the examination. Despite that profound loss, the Department is yet to act."

Instead of devoting their time to teaching, teachers often waste time trying to prevent incidents of school violence because they need to be aware of developing issues before they turn into violent situations. This requires teachers to 
focus on learner interaction, both in the classroom and during social interactions between learners during breaks and recreation. Developing social issues are evident in arguments between learners and teachers, but are also less obvious in subtle behaviour, such as mumbled remarks and certain mannerisms in the classroom. Teachers need to be proactive and confront these issues before they erupt into violent situations in schools (Posner, 1995). A teacher from the Sibasa circuit in the Vhembe district reported the following incident:

\begin{abstract}
"It was the case where a male student had pointed a gun at him, and he had to remain calm. With his life under threat, this was a daunting task. Despite his fear, he realised that panic would not clarify the situation, but would exacerbate it. Although the nearest police station was informed about the disaster; it took a long time for the police to come to the victim's rescue."
\end{abstract}

While some school safety issues may be averted by forbidding learners to bring certain items into the classroom, some find the searching of students problematic.

"In the study, a case of a teacher being punched in Queenstown district whist searching a Grade 12 student was also reported. There was absolute pandemonium in the class and students were not taught that day."

These students were under the influence of liquor and dagga. The banning of school bags and long coats could prevent students from concealing weapons, harmful objects, drugs and intoxicating liquor and bringing them into the classroom. Unfortunately, because pistols are small, it is fairly easy for learners to conceal them in the classroom. In addition to banning book bags and weapons from the classroom, restrictions on recreational items such as cameras, cell phones and music players could help ensure school safety. Such restrictions would help learners to focus on their school work, at the same time, preventing theft, which often leads to fights breaking out among learners. Although such incidents have been reported to the police, this has not really helped the situation. Principals have to spend a lot of their time as watchdogs over learners and teachers in the school. When learners and teachers are injured on school premises, it is the principals who are held to account. Avoiding negative behaviour that could result in public embarrassment is essential for principals and others in role model positions.

\title{
4.2 Theme 2: lack of job security
}

Job security is essential for principals and teachers employed by the Department of Basic Education. However, with economic meltdown, hiring freezes have become the order of the day. Teachers as government employees play a vital role that cannot be ignored and certainly not underfunded. However, the reality is that currently, teaching jobs in South Africa are less secure than at any time since the economic depression, even though the country is rallying after the present recession. In fact, temporary appointments in many districts in the Eastern Cape and Limpopo are more prevalent now than they were during the worst of the recession.

In 2011, 11500 teachers were absorbed by different schools in the Eastern Cape and Limpopo on short-term contracts, resulting in job insecurity, the loss of potential holiday pay and the inability for some to take out car and home loans. Of those on contracts, $90 \%$ of these teachers had to reapply for positions and this had a negative effect on their teaching. It is appalling that lack of tenure was the most important issue they faced. Any teacher who does not have a permanent job, lacks job security and as such, will inevitably seek greener pastures. As soon as such a teacher receives a better offer from another institution or organisation, he or she is likely to immediately leave the profession. This is harmful to the South African economy and an inconvenience to parents of learners who are left without a teacher for a long period of time. The plea of the South African Democratic Teachers Union that such teachers be appointed permanently fell on deaf ears. The services of all these teachers had to be terminated towards the end of the year because no funds had been set aside to retain new staff. This was a top-down approach. The principal from school $X$ in the King Williams Town district, with 0\% pass rate, reported the following:

"In my school, 3 competent Grade 12 teachers who taught Mathematics and Physical Science were among the 6000 teachers who lost their jobs in 2012. These teachers had good track records of obtaining 100\% pass rate annually. For six months, students stayed without teachers. I was not surprised to get $0 \%$ pass rate because there was no support from the provincial department. Despite several reminders, it fell into deaf ears. South Africa will continue facing critical skills shortages in areas such as engineering and medicine."

A concerned teacher from Lusikisiki stated the following: 
"Right now, I think working a secure job for minimum wage is more preferable to working in education and going from contract to contract with periods of unemployment in between contracts. I am disappointed in the system ... I cannot dream of purchasing a car, never mind a mortgage, as I do not know if I will have a job in January. What about my family? I am perturbed and I have to teach haphazardly."

In 2012, teachers' unions reported that the Department of Education in the Eastern Cape and Limpopo had a shortage of 5700 teachers, but only 725 were appointed. Not only was this stressful to those teachers who were breadwinners, but it affected their family members too. This obviously has a negative impact on the Grade 12 results because learners cannot learn without teachers. In striving for job security, teachers try to be dedicated and committed to their education system, and they focus their skills and capabilities on being consistent performers. Without similar commitment on the part of the authorities, the system seems destined to lose them. One principal commented as follows:

\begin{abstract}
"It would stand to reason that the Department of Education in the EC might have learnt a lesson when the province returned the country's worst Grade 12 results for two years in succession. However, it seems to have learnt no such lesson and as things stand, the picture remains gloomy. Indeed, should the provincial Department not heed the call of the teachers' unions, to reinstate all the 6000 teachers who lost their jobs in 2011, the worst should be expected in future as well."
\end{abstract}

Common union membership meant that teachers and principals regarded themselves as allies. Unionisation also offered principals job security and limited autonomy; to operate schools in order to meet learners' needs and with less fear of reprisal from school governing bodies and parents. In this regard, Gronn (2000) argues that job stability and medium- to long-term job security ensure that teachers are extrinsically motivated enough to be committed to the vision of the school and to reap the commensurate rewards and benefits. Unsatisfied principals and teachers are more likely to leave their schools. When this happens, they leave behind a void of lost skills. In addition, the cost of replacing them is extremely high. The attrition rate among teachers means additional expenses because replacements must be hired and trained, something that could have been avoided, had the employees been satisfied in their profession. As long as teachers are dissatisfied, they will feel rejected, and this could engender feelings of anger and hatred towards for the entire school. Dissatisfied teachers will not exhibit qualities of citizenship towards their schools and will not go the extra mile to assist the school, even if this falls within their scope of duty. Job security relieves stress and burnout, a syndrome of emotional exhaustion and cynicism that occurs frequently among individuals whose fears about their future are not allayed. Burnout in the workplace has increased dramatically and is caused by workaholic behaviour of constant pressure and stress (Charon, 2001; Whitaker, 2002). To relieve such stress, schools should encourage, compliment and support teachers. Principal Y from Qumbu reported the following;

\begin{abstract}
'Teachers' unions are always up in arms with the department's negative attitude towards teachers. Principals have to account when students fail. The departmental officials hire and fire you whenever they please. This is disgusting. Last year 3 principals were relieved of their duties because Grade 12 students' failure rate was high. In 2013, there are no support mechanisms."
\end{abstract}

Building a positive, shared vision in a toxic culture or in a school with negative subcultures is extremely difficult. Where this is necessary, the instructional leader should endeavour to revamp the school. This may involve confronting negativity and underlying assumptions head on. As long as jobs for teachers are permanently guaranteed, they are able to plan. It may also require working with existing staff to help them become more collaborative, to believe in their learners and to support the core vision of the school. It also necessitates a careful and focused hiring process that recruits, selects and develops staff who not only have fine teaching skills, but who also believe in the school's vision (Bennett, 2001). The role of principals is to implement the policies of a central authority or to respond to the unique needs of a community. Job security is undoubtedly more important than a monthly wage. With job security, teachers can put all their energy into their teaching.. Without job security, the principal and teachers are tormented with the fear of losing their jobs, which ultimately affects their performance. Personal factors such as education, work experience, job functional area and work location, play a key role in determining the need for a teacher's services, and have an impact on teachers' personal job security.

Since job security depends on having the skills and experience needed by the employer, which in turn depend on the prevailing economic condition and business environment, teachers whose services are required by the Department will enjoy greater job security. Teachers feel insecure because they know that the government has the budget for education, but is not willing to spend it on human capital. Profits are approaching prerecession levels, but not because more teachers are employed. The converse is true,, and this is a recipe for insecurity.

As long as the allocation of resources remains as skewed as it is, with the majority of rural schools being built from 
grass and thatch, with no running water, electricity, modern technical equipment and affordable transport for learners and teachers, effective teaching will always be a pipe dream. A teacher is a tabula rasa without something to teach. That something comes from a learning content with a background. The learning content comes from resources that create the bulk of understanding surrounding the particular learning area. Hence teachers in the Eastern Cape and Limpopo, like all teachers worldwide, work better if they have resources to support them. Resources help learners to understand the overall aim of the lesson the teacher is trying to convey. Moreover, such resources enable teachers to give feedback on whether learners have improved their understanding of the given subject.

A lack of resources can make the whole teaching process boring and ineffective. The basic purpose of a teacher is to convey information from one medium, such as a textbook, to the learners through contents that they can relate to. These contents can stem from many sources, but should come mainly from the teacher support provided through the school and the curriculum. Resources can also help the teachers get the learning content across to learners. Sometimes teaching can be "lost in translation", when the learners feel that they do not quite understand what the teacher is trying to say about a subject. Resources, in this instance, can provide a strong language base from which the teachers can draw, fostering better verbal understanding between teacher and learner. Teachers realise that they have been asked to do more with less help, and no matter how hard they work or how much money the government makes, the likelihood of a smaller future workforce seems to be on the cards. The Department of Basic Education needs to attend to this urgent matter.

\section{Recommendations}

\subsection{Safety measures}

It is imperative that all learners and teachers feel safe in schools, before and after a crisis has occurred. If necessary, the school system must provide psychological services and support to students and staff. These services should be provided by school psychologists certified by the Department of Health. All visitors must sign in and wear an identity card. An intrusion alarm should be introduced in all provincial schools. There should be a crisis response team and security personnel with selected members who undergo training to enable them to respond appropriately to a variety of potential school emergencies. The security guards on duty should have emergency radios to receive updates on emergency situations. All exterior school doors should be locked and CCTV systems should be installed. Learners' school bags should always be checked before they are allowed into classrooms. Scholar transport should also be made available for students who live far from schools.

\subsection{Job security}

The Department of Basic Education should no longer appoint teachers on a contractual basis because this has a negative effect on teachers' productivity.. Fixed-term contracts could be used to replace teachers on maternity or long service leave, to replace teachers who are seconded to other roles or to fill positions in schools with declining enrolments. A teacher with a high level of job security will often perform and concentrate better than a teacher who is in constant fear of losing his or her job. Although this fear may increase motivation in certain situations, a lack of job security can be a source of distraction and result in excess stress and low morale that hinders teachers' overall performance. This situation will invariably affect the Grade 12 students and have a negative impact of their results.

\section{Conclusion}

From the foregoing discussion, it is evident that the low 2010 to 2013 Grade 12 pass rate in the Eastern Cape and Limpopo was the result of multifaceted problems facing the South African education system. In this study, the role of school principals in addressing the above-mentioned challenges was examined, in the light of principals' role as the chief executive officers who manage school finances and endeavour to raise funds; complement the provincial department's efforts; and provide and maintain physical facilities. Principals are curriculum and instruction supervisors and change agents. Perhaps the most important role the principal fulfils in curriculum leadership is assisting teachers to implement the curriculum, because even the best official curriculum is worthless unless it can be successfully applied by teachers. Quality leaders produce excellent results. Highly effective teachers and their professional learning do make a difference in the classroom. It is not so much what learners bring with them from their backgrounds, but what they experience on a day-to-day basis in their interactions with teachers and their fellow learners. Teaching quality has a profound effect on 
learners' experience of schooling, including their attitudes, behaviour and achievement outcomes. Grade 12 results will only improve if there is order and discipline in the schools in the Eastern Cape.

\section{References}

Bennett, A. 2001. Critical issues for principals. Chicago: Roosevelt University.

Charon, J. (2001). Symbolic interactionism: An introduction, an interpretation, integration. Upper Saddle River, NJ: Prentice Hall.

Duignan, P. 2006. Educational leadership: key challenges and ethical tensions. Melbourne: Cambridge University Press.

Glickman, C., Gordon, S. \& Ross-Gordon, J. (2001). Supervision and instructional leadership: a developmental approach. Boston, MA: Allyn \& Bacon.

Gronn, P. (2000). Distributed properties: A new architecture for leadership. Educational Management and Administration 28(3).

Guba, E. \& Lincoln, Y. (1994). Competing paradigms in qualitative research. In N. Denzin \& Y. Lincoln (Eds), Handbook of qualitative research (pp.105-117). Thousand Oaks, CA: Sage.

Gurr, D. (2001). Directions in educational leadership. Hot Topics, 5 (edited by P. White). Available at: www.qcel.edleaders.edu.au /pubs/52001.html

Leithwood, K. \& Jantzi, D. (2000). The effects of transformational leadership on organisational conditions and student engagement with School. Journal of Educational Administration, 38.

Maehr, M.L. (1991). The "psychological environment" of the school: A focus for school leadership. In P.W. Thurston \& P.P. Zodhiates (Eds), Advances in educational administration, volume 2: School leadership (pp. 51-81). Greenwich, CT: JAI Press.

Murphy, J. (1990). Principal instructional leadership. In P.W. Thurston \& L.S. Lotto (Eds), Advances in educational administration, volume 1 (part B): Changing perspectives on the school (pp. 163-200). Greenwich, CT: JAI Press.

Posner, G. (1995). Analyzing the curriculum. New York: McGraw-Hill.

Whitaker, K. (2002). Principal role changes and influence on principal recruitment and selection: An international perspective. Journal of Educational Administration, 41(1), 37-54. 